This page intentionally left blank 


\section{FUNGIBLE LIFE}

EXPERIMENT IN THE ASIAN CITY OF LIFE

\section{AIHWA ONG}

Duke University Press Durham and London 2016 
(C) 2016 Duke University Press

All rights reserved

Printed in the United States of America on acid-free paper $\infty$ Cover designed by Amy Ruth Buchanan

Typeset in Arno Pro by Westchester Publishing Services

Library of Congress Cataloging-in-Publication Data

Names: Ong, Aihwa, author.

Title: Fungible life : experiment in the Asian city of life /

Aihwa Ong.

Description: Durham : Duke University Press, 2016. | Includes bibliographical references and index.

Identifiers: LCCN 2016021420 (print)

LCCN 2016023363 (ebook)

ISBN 9780822362494 (hardcover : alk. paper)

ISBN 9780822362647 (pbk. : alk. paper)

ISBN 9780822373643 (e-book)

Subjects: LCSH: Biopolis (Singapore) | Research parks-

Singapore. | Medical sciences-Research-Asia. |

Biotechnology_Political aspects-Asia. | Biotechnology-

Moral and ethical aspects-Asia.

Classification: LCC HD9999.B443 S555 2016 (print) | LCC

HD9999.B443 (ebook) | DDC 338.4/76151095957—dc23

LC record available at https://lccn.loc.gov/2016021420

Cover art: A sculpture at Biopolis, 2003. AP Photo /

Wong Maye-e. 
In memory of my parents Ong Chin Seng and P'ng Hooi Kean 
This page intentionally left blank 